\title{
Risk factors for Type 2 Diabetes Mellitus in college students: association with sociodemographic variables ${ }^{1}$
}

\author{
Adman Câmara Soares Lima² \\ Márcio Flávio Moura Araújo ${ }^{3}$ \\ Roberto Wagner Júnior Freire de Freitas ${ }^{4}$ \\ Maria Lúcia Zanetti ${ }^{5}$ \\ Paulo César de Almeida ${ }^{6}$ \\ Marta Maria Coelho Damasceno ${ }^{7}$
}

Objective: identify the modifiable risk factors for type 2 diabetes mellitus in college students and associate these factors with their sociodemographic variables. Method: cross-sectional study, involving 702 college students from Fortaleza-CE, Brazil. Sociodemographic, anthropometric, physical exercise data and blood pressure and fasting plasma glucose levels were collected. Results: the most prevalent risk factor was sedentariness, followed by overweight, central obesity, high fasting plasma glucose and arterial hypertension. A statistically significant association was found between overweight and sex $(p=0.000)$, age $(p=0.004)$ and marital status $(p=0.012)$, as well as between central obesity and age $(p=0.018)$ and marital status $(p=0.007)$ and between high fasting plasma glucose and sex $(p=0.033)$. Conclusion: distinct risk factors were present in the study population, particularly sedentariness and overweight.

Descriptors: Risk Factors; Diabetes Mellitus, Type 2; Students; Nursing; Health Promotion.

\footnotetext{
${ }_{1}^{1}$ Supported by Conselho Nacional de Desenvolvimento Científico e Tecnológico (CNPq), process \# 474902/2009-9.

2 Doctoral student, Universidade Federal do Ceará, Fortaleza, CE, Brazil. Professor, Faculdade de Ensino e Cultura do Ceará, Fortaleza, CE, Brazil. ${ }^{3} \mathrm{PhD}$, Adjunct Professor, Universidade da Integração Internacional da Lusofonia Afro-Brasileira, Acarape, CE, Brazil.

${ }^{4}$ PhD, Adjunct Professor, Centro de Ciências da Saúde, Universidade Federal do Piauí, Floriano, PI, Brazil.

${ }^{5}$ PhD, Associate Professor, Escola de Enfermagem de Ribeirão Preto, Universidade de São Paulo, WHO Collaborating Centre for Nursing Research Development, Ribeirão Preto, SP, Brazil.

${ }^{6}$ PhD, Collaborating Professor, Centro de Ciências da Saúde, Universidade Estadual do Ceará, Fortaleza, CE, Brazil.

${ }^{7} \mathrm{PhD}$, Adjunct Professor, Universidade Federal do Ceará, Fortaleza, CE, Brazil.
}

Corresponding Author:

Adman Câmara Soares Lima

Rua Alexandre Baraúna, 949

Bairro Engenheiro Luciano Cavalcante

CEP: $60430-160$, Fortaleza, CE, Brasil

E-mail: adminhacs@hotmail.com
Copyright (c) 2014 Revista Latino-Americana de Enfermagem This is an Open Access article distributed under the terms of the Creative Commons Attribution Non-Commercial License (CC BY-NC).

This license lets others distribute, remix, tweak, and build upon your work non-commercially, and although their new works must also acknowledge you and be non-commercial, they don't have to license their derivative works on the same terms. 


\section{Introduction}

Lifestyle changes among the peoples of all countries have contributed to the ascent of type 2 diabetes mellitus (DM2) cases in different age groups. In recent decades, the prevalence of DM2 has been increasing, which is characterized as a global epidemic and a public health problem ${ }^{(1)}$.

The risk of developing this disease increases among sedentary people, suffering from overweight, central obesity, arterial hypertension fasting plasma glucose $\geq 100 \mathrm{mg} / \mathrm{dl}$, inappropriate eating habits, advanced age, and also with a family history of diabetes, which is considered a non-modifiable risk factor ${ }^{(2)}$.

Public health policies have recommended the early identification of the risk factors for DM2 and the combat of those that can be modified, with a view to the implementation of interventions that can slow down or impede the manifestation of the disease and reduce public health spending(2-3).

Therefore, researchers in the theme have been developing studies that initially investigated the risk factors for DM2 in middle-aged adults, who used to be considered more vulnerable ${ }^{(4-5)}$. The outbreak of DM2 in children and adolescents, however, determined the search for risk factors in those population groups ${ }^{(6-7)}$.

In Fortaleza-CE, a city in the Brazilian Northeast, a group of nurses have been investigating the risk factors for DM2 in different population segments. Thus, factors were identified in health workers $^{(8)}$ and the prevalence of these factors in children and adolescents is already known ${ }^{(9-10)}$.

Although in a limited manner, the literature also shows studies that identify risk factors for DM2 in college students ${ }^{(11-12)}$. Therefore, it is of interest in this research to identify risk factors for DM2 in college students from Fortaleza-CE.

All phases of life are important to investigate the presence of conditions that can trigger future illnesses. When they enter university, however, students go through different lifestyle changes that can favor the appearance of one or more risk factors for DM2 and other chronic illnesses. In addition, these are people who are getting prepared to enter the job market in the near future.

Developing this research means, at the same time, identifying risk behaviors for the students' health and offering support for the planning and implementation of interventions that permit preventing or postponing the appearance of DM2. In addition, the contribution to the establishment of indicators is highlighted in the elaboration of public policies.

The objective in this study was to identify modifiable risk factors for DM2 in college students from Fortaleza$\mathrm{CE}$, Brazil and associate them with sociodemographic variables.

\section{Methods}

A cross-sectional study was undertaken at Universidade Federal do Ceará (UFC). The sample was calculated using a formula for infinite populations. A $50 \%$ prevalence rate was adopted to provide a maximum sample size, as well as a significance level of $a=0.05$ and an absolute sampling error of $4 \%$. To mitigate possible losses, $10 \%$ was added to the sample size ( $N=702$ college students), distributed among the following knowledge areas of the institution: human sciences, exact sciences, agriculture sciences, health sciences, sciences and technology. Based on the population per knowledge area, the sample was stratified and 143, $116,98,106,127$ and 112 students were investigated, respectively.

In the human science area, the courses Pedagogics, Social Sciences and Languages were investigated: in exact sciences, Business Administration, Economics and Accountancy; in agriculture sciences, Zootechnics, Agronomy and Fishing Engineering; in health sciences, Nursing and Pharmacy; in sciences, Chemistry, Geography and Biological Sciences; and in technology, Electrical, Civil and Metallurgic Engineering.

The following inclusion criteria were established: college students properly enrolled in face-to-face, daytime undergraduate programs; living in Fortaleza-CE, Brazil and having a contact telephone and e-mail. The exclusion criteria were: being pregnant and indicating oneself as a diabetes mellitus patient.

The following sociodemographic variables were considered: sex (male and female); age (16-58 years); ethnic origin (white, mulatto, black, Asian); marital status (married/fixed partner, single, widowed, separated/divorced); professional situation (studies only, studies and works); course term (term the student is taking); novice (taking the first half of the program); veteran (taking the second half of the program); economic class (A1, A2, B1, B2, C, D, E according to the Brazilian Economic Classification Criteria of the Associação Brasileira de Empresas e Pesquisas) and whom the student lives with (parents, family members, friends, partner/companion, alone) ${ }^{(13)}$. 
The following outcome variables were selected: sedentariness (students who exercise less than 30 minutes and less than three times per week $^{(14)}$; excess weight (overweight with BMI between 25.0 and $29.9 \mathrm{~kg} / \mathrm{m}^{2}$ and obese with BMI over $30 \mathrm{~kg} / \mathrm{m}^{2}$, according to World Health Organization recommendations ${ }^{(14)}$; central obesity: abdominal circumference (AC) over $102 \mathrm{~cm}$ in men and over $88 \mathrm{~cm}$ in women) ${ }^{(14)}$; arterial hypertension (systolic blood pressure levels of $140 \mathrm{mmHg}$ of higher and diastolic BP levels of $90 \mathrm{~mm} /$ $\mathrm{Hg}$ or higher; besides levels of $140 \mathrm{~mm} / \mathrm{Hg}$ or higher, indicating isolated systolic hypertension(15); high fasting plasma glucose $(100 \mathrm{mg} / \mathrm{dl}$ or higher)(3).

To collect the data, the field researchers received a 30-hour training: two Ph.D. students, two M.Sc. students and two scientific initiation grantees, in order to guarantee the reliability of the data. The data were collected between September and November 2010 and between February and June 2011, in private rooms at the university.

The college students were recruited in the classrooms after receiving clarifications about the research objectives and methods. The students who agreed signed the Free and Informed Consent Form and answered the questionnaire about the sociodemographic data and physical exercise practice. In addition, a day and time were scheduled to measure the weight, heiht, blood pressure (BP), abdominal circumference, as well as to collected the fasting plasma blood. On the day before the appointment, the researchers contacted the students to remind them about the need to fast.

Portable scales were used to measure the weight and an inelastic metric tape attached to the wall for the height. The students were oriented to remove their shoes and remain standing still, with their hands resting on their thighs and their head adjusted to the Frankfurt plane. The abdominal circumference (AC) was measured using a non-elastic metric tape placed on the skin at the midpoint between the final rib and the upper end of the iliac crest at the end of the expiration movement ${ }^{(14)}$. The blood pressure was verified according to the Brazilian guidelines elaborated for that purpose ${ }^{(15)}$. The blood collection as done by a specialized and previously hired laboratory, complying with orders to preserve the samples and the subjects' safety. All students were informed of the results by e-mail and participants who presented at least one risk factor for DM2 received the recommendation to visit a health service.

The collected data were organized in a Microsoft Excel worksheet, using triple data entry and further validation, in order to control for possible errors in the transfer of the information. Central trend measures were calculated for the continuous variables. To analyze the associations among variables, the non-parametric Chi-square $\left(\chi^{2}\right)$ test and the likelihood ratio were employed. The data were processed in the statistical software Statistical Package for the Social Sciences (SPSS) version 18.0. The project received approval from the Ethics Committee for Research Involving Human Beings at Universidade Federal do Ceará under protocol 208/10.

\section{Results}

Among the 702 college students, $62.7 \%$ were women; $53.3 \%$ in the age group between 20 and 24 years (21.5 SD=1.57); $49.3 \%$ mulatto; $92.3 \%$ single; $69.1 \%$ were taking the first to fifth course term; 71.2 $\%$ lived with their parents and $65.2 \%$ did not work. The economic classes B and C were predominant (39.5\%), respectively, with a monthly family income of $U \$$ $1,705(S D=200)$. This variable showed an asymmetric distribution to the right (Kolmogorov Smirnov with p<0.001) (Table 1).

Table 2 shows that the most prevalent risk factor for DM 2 was sedentariness, followed by overweight, central obesity, high fasting plasma glucose and arterial hypertension.

As regards the investigated risk factors for DM2 and the sociodemographic variables, it was verified that sedentariness levels were higher in women (77.6\%), in the age range from 20 to 24 years $(71.3 \%)$, novices (71.9\%), single $(71.2 \%)$ and in socioeconomic class $C$ (74.4\%). A statistically significant association was found with sex only though $(p<0.001)$.

Overweight was predominant among men $(32.1 \%)$, in the age range between 25 and 58 years (34.1\%), married $(29.3 \%)$, veterans $(24.4 \%)$ and in economic classes D and E (22.9\%). Obesity was more frequent among men $(7.6 \%)$, in the age range between 25 and 58 years (10.6\%), married (14.6\%), veterans $(7 \%)$ and in economic class A (10.8\%). Obesity increased with age, while overweight was practically similar in the age groups between 18 and 19 and between 20 and 24 years. Hence, overweight prevailed among men, married and in the age range between 25 and 58 years. A statistically significant association was found between overweight and sex $(p=0.000)$, age $(p=0.004)$ and marital status $(p=0.012)$, respectively. 
Table 1 - Distribution of the number of college students according to the sociodemographic variables, Fortaleza, CE, Brazil, 2011

\begin{tabular}{|c|c|c|c|}
\hline Variable & $\mathbf{N}$ & $\%$ & Mean $\pm S D$ \\
\hline \multicolumn{4}{|l|}{$\operatorname{Sex}(N=702)$} \\
\hline Female & 440 & 62.7 & \\
\hline Male & 262 & 37.3 & \\
\hline Age range $(\mathrm{N}=696)$ & & & $21.5 \pm 4.5$ years \\
\hline $16-19$ & 237 & 34.1 & \\
\hline $20-24$ & 374 & 53.7 & \\
\hline $25-58$ & 85 & 12.1 & \\
\hline \multicolumn{4}{|l|}{ Term $(\mathrm{N}=687)$} \\
\hline Novices & 485 & 70.6 & \\
\hline Veterans & 202 & 29.4 & \\
\hline \multicolumn{4}{|l|}{ Marital status $(\mathrm{N}=690)$} \\
\hline Married/Fixed partner & 42 & 6.1 & \\
\hline Single & 648 & 93.9 & \\
\hline \multicolumn{4}{|l|}{ Employment Situation } \\
\hline Only studies & 454 & 65.2 & \\
\hline Studies and works & 242 & 54.8 & \\
\hline Economic class $(\mathrm{N}=698)$ & & & $\mathrm{R} \$ 3,211.7 \pm \mathrm{R} \$ 3,765.50$ \\
\hline A & 74 & 10.6 & \\
\hline B & 277 & 39.7 & \\
\hline C & 277 & 39.7 & \\
\hline $\mathrm{D}$ & 70 & 10.0 & \\
\hline \multicolumn{4}{|l|}{ Lives with } \\
\hline Parents & 494 & 71.2 & \\
\hline Family members & 118 & 17.0 & \\
\hline Friends & 27 & 3.9 & \\
\hline Companions & 35 & 5.0 & \\
\hline Alone & 20 & 2.9 & \\
\hline
\end{tabular}

Central obesity levels were similar among men and women $(5.0 \%$ and $5.7 \%)$, respectively, and prevailed in the age range from 25 to 58 years $(11.8 \%)$ and among married people or who lived with a fixed partner (14.6\%). The statistically significant association between central obesity and age $(p=0.018)$ and marital status $(p=0.007)$ is highlighted.

Most cases of arterial hypertension were found in men (7.1\%). A statistically significant association was found between arterial hypertension and $\operatorname{sex}(p<0.001)$. In this respect, the percentages of men and women were close (15.7\% and $10.2 \%)$, respectively. A statistically significant association was found between high fasting plasma glucose and sex $(p=0.033)$.

As regards the risk factors for DM2 and the knowledge areas, the prevalence levels of sedentariness were high in all areas. The lowest level (65.5\%) was found in exact sciences and the highest (75.2\%) in health, without a statistically significant difference between the proportions though $(p=0.586)$. Concerning the overweight, the area in which the highest percentages of students were identified were sciences (31.5\%) and the lowest in health $(p=0.014)$. The prevalence of central obesity was equitably distributed among the areas $(p=0.097)$, ranging from $0 \%$ in health to $7.9 \%$ in sciences. The highest prevalence of hypertension was found in sciences (11.8\%) and the lowest in health $(2.8 \%) \quad(p=0.080)$. High fasting glucose revealed different proportions among the areas $(p<0.0001)$, ranging from $28.2 \%$ in technology to $6.6 \%$ in health.

Table 2 - Prevalence of risk factors for type 2 diabetes mellitus, Fortaleza, CE, Brazil, 2011

\begin{tabular}{|c|c|c|c|c|c|c|c|c|c|c|}
\hline \multirow[t]{2}{*}{ Variable } & \multicolumn{2}{|c|}{ Sedentariness } & \multicolumn{2}{|c|}{$\begin{array}{l}\text { Overweight } \\
(\%)\end{array}$} & \multicolumn{2}{|c|}{$\begin{array}{c}\text { Central obesity } \\
\text { (\%) }\end{array}$} & \multicolumn{2}{|c|}{$\begin{array}{c}\text { Arterial } \\
\text { Hypertension (\%) }\end{array}$} & \multicolumn{2}{|c|}{$\begin{array}{l}\text { High glucose } \\
(\%)\end{array}$} \\
\hline & $\%$ & $p$ & $\%$ & $\mathrm{p}$ & $\%$ & $p$ & $\%$ & $\mathrm{p}$ & $\%$ & p \\
\hline Sex & & $<0.0001^{*}$ & & $<0.0001^{*}$ & & $0.045^{\star}$ & & $<0.0001^{*}$ & & $0.033^{*}$ \\
\hline Female & 77.6 & & 18.9 & & 4.1 & & 0.9 & & 10.2 & \\
\hline Male & 59.0 & & 39.7 & & 7.6 & & 18.3 & & 15.7 & \\
\hline Age range & & 0.853 & & $<0.0001^{*}$ & & $0.024^{*}$ & & 0.236 & & 0.697 \\
\hline $16-19$ & 70.6 & & 22.8 & & 3.0 & & 6.3 & & 13.8 & \\
\hline $20-24$ & 71.3 & & 24.6 & & 5.3 & & 7.0 & & 11.9 & \\
\hline $25-58$ & 68.2 & & 44.7 & & 10.6 & & 11.8 & & 10.7 & \\
\hline Term & & 0.182 & & 0.054 & & 0.097 & & 0.195 & & 0.811 \\
\hline Novices & 71.9 & & 24.5 & & 4.3 & & 6.6 & & 12.2 & \\
\hline Veterans & 66.8 & & 31.7 & & 7.4 & & 9.5 & & 7.3 & \\
\hline Marital status & & 0.534 & & $0.005^{*}$ & & $0.001^{*}$ & & 0.245 & & 0.312 \\
\hline Married/Fixed partner & 66.7 & & 45.2 & & 16.7 & & 12.2 & & 7.3 & \\
\hline Single & 71.2 & & 25.3 & & 4.6 & & 7.3 & & 4.5 & \\
\hline Economic class & & 0.131 & & 0.804 & & 0.072 & & 0.859 & & 0.393 \\
\hline A & 62.2 & & 31.1 & & 10.8 & & 9.5 & & 11.1 & \\
\hline B & 68.2 & & 26.0 & & 3.2 & & 7.2 & & 14.5 & \\
\hline
\end{tabular}

(continue...) 
Table 2 - (continuation)

\begin{tabular}{|c|c|c|c|c|c|c|c|c|c|c|}
\hline \multirow[t]{2}{*}{ Variable } & \multicolumn{2}{|c|}{ Sedentariness } & \multicolumn{2}{|c|}{$\begin{array}{c}\text { Overweight } \\
(\%)\end{array}$} & \multicolumn{2}{|c|}{$\begin{array}{c}\text { Central obesity } \\
(\%)\end{array}$} & \multicolumn{2}{|c|}{$\begin{array}{c}\text { Arterial } \\
\text { Hypertension (\%) }\end{array}$} & \multicolumn{2}{|c|}{$\begin{array}{l}\text { High glucose } \\
(\%)\end{array}$} \\
\hline & $\%$ & $p$ & $\%$ & $\mathbf{p}$ & $\%$ & $p$ & $\%$ & $\mathbf{p}$ & $\%$ & $p$ \\
\hline C & 74.4 & & 26.0 & & 6.1 & & 7.6 & & 10.0 & \\
\hline $\mathrm{D}$ & 74.3 & & 28.6 & & 5.7 & & 5.7 & & 14.5 & \\
\hline Knowledge area & & 0.586 & & 0.014 & & 0.097 & & 0.080 & & $<0.0001$ \\
\hline Agriculture & 70.1 & & 26.5 & & 6.1 & & 4.1 & & 12.4 & \\
\hline Sciences & 71.7 & & 31.5 & & 7.9 & & 11.8 & & 13.6 & \\
\hline Exacts & 65.5 & & 28.4 & & 5.2 & & 8.6 & & 11.4 & \\
\hline Human & 73.4 & & 28.0 & & 7.7 & & 6.3 & & 3.6 & \\
\hline Health & 75.2 & & 12.3 & & - & & 2.8 & & 6.6 & \\
\hline Technology & 67.3 & & 31.3 & & 4.5 & & 9.8 & & 28.2 & \\
\hline
\end{tabular}

*The proportions are different and statistically significant

Sedentariness was the most prevalent risk factor for DM2 (65.1\%) among the students with only one risk factor $(p<0.0001)$. For the students with two factors, the most prevalent risk factors were overweight ( $41.2 \% ; \mathrm{p}<0.0001)$, hypertension $(53.8 \%$; $p=0.003)$ and glucose $(49.4 \% ; p<0.0006)$; among the students with three factors, hypertension was the most prevalent $(39.5 \%)$, but without statistical significance $(p=0.246)$. Among the students with four risk factors, obesity was the most prevalent $(18.4 \%)$, but without statistical significance.

Table 3 - Distribution of risk factors according to the number of factors, Fortaleza, CE, Brazil, 2011

\begin{tabular}{|c|c|c|c|c|c|c|c|c|c|}
\hline \multirow{3}{*}{ Risk factor } & \multicolumn{8}{|c|}{ Number of factors } & \multirow{3}{*}{$\mathbf{p}$} \\
\hline & \multicolumn{2}{|c|}{1} & \multicolumn{2}{|c|}{2} & \multicolumn{2}{|c|}{3} & \multicolumn{2}{|c|}{4} & \\
\hline & $\mathbf{N}$ & $\%$ & $\mathbf{N}$ & $\%$ & $\mathbf{N}$ & $\%$ & $\mathbf{N}$ & $\%$ & \\
\hline Sedentariness & 321 & 65.1 & 113 & 22.9 & 49 & 9.9 & 10 & 2.0 & $<0.0001$ \\
\hline Overweight & 48 & 25.7 & 77 & 41.2 & 52 & 27.8 & 10 & 5.3 & $<0.0001$ \\
\hline Central obesity & 4 & 10.5 & 12 & 31.6 & 15 & 39.5 & 7 & 18.4 & 0.246 \\
\hline Hypertension & 5 & 9.6 & 28 & 53.8 & 15 & 28.8 & 4 & 7.7 & 0.003 \\
\hline Glucose & 13 & 15.3 & 42 & 49.4 & 24 & 28.2 & 6 & 7.1 & $<0.0006$ \\
\hline
\end{tabular}

\section{Discussion}

The most prevalent risk factor for DM2 was sedentariness, which was also predominant among the investigated women, confirming the results of Brazilian and international studies involving college students ${ }^{(11,16)}$. On the other hand, data from the Brazilian Ministry of Health indicate similar percentages of lack of physical exercise among male and female adults ${ }^{(17)}$.

Although the problems deriving from the lack of physical exercise have been widely disseminated in the global media nowadays, and the cult of the body is predominant, resistance against exercising still permeates daily life in Brazil. The main justifications for this conduct are lack of time, motivation or tiredness, related to the workday ${ }^{(17)}$.

College students in general, independently of the course they are affiliated with, are involved in intense classes throughout the program, often combined with extracurricular training or even work. Nevertheless, a substantial part of the sample only studied, which can permit the planning of exercise times.

Excess weight, including overweight and obesity, also stood out in this study, in accordance with studies on the theme(12). In addition, it was predominant among men, exemplifying studies undertaken in Brazil as well as on other continents, indicating that, independently of the country, the daily habits that lead to the appearance of this risk factor for DM2 are similar(12,18).

Overweight and obesity involve a complex network of triggering factors, such as sedentariness, inappropriate eating habits, cultural and environmental issues, which may justify results of studies that indicated the predominance of excess weight in women ${ }^{(19)}$.

Excess weight showed statistically significant associations with age and marital status. Most college students were young adults, confirming the 
early appearance of overweight and obesity in this development phase and increasing with age.

The relation between excess weight and the marital status was confirmed in other studies, but has not been sufficiently clarified yet, revealing a knowledge gap (20-21).

The levels detected for central obesity, blood pressure and glucose were similar to other publications reviewed(22-25). The predominance of adiposity among women and of high blood pressure and glucose among men is also similar to other studies involving college students ${ }^{(22-25)}$.

The statistically significant association found between risk factors for DM2 and knowledge areas cannot be discussed due to the lack of literature, leaving this relation so far unknown and representing a challenge for future studies.

Hence, in the future, beyond the quantitative data, it is important to discover the nuances related to the gender and age range of this social group, which prevent them from following an appropriate diet and practicing physical exercise regularly. Issues like an unfavorable academic infrastructure for a healthy diet or a lack of areas for physical exercise, the time spent on digital technologies or the cult of practicality and speed in the preparation of meals. All of these can represent reflections to clarify the continuing high percentages of sedentariness and overweight in such a young and knowledgeable part of society.

Investigating modifiable risk factors for DM2 independently of the target population implies the performance of procedures that are mainly inherent in Nursing practice. In that context, a tool like anthropometrics is highlighted, which should increasingly be used in the nursing consultations. Its advantages include low cost, easy application and availability of material at all health services.

\section{Conclusion}

The data found in this study indicated that the most prevalent risk factor was sedentariness, followed by overweight, central obesity, high fasting plasma glucose and arterial hypertension. A statistically significant association was found between excess weight and sex $(p=0.000)$, age $(p=0.004)$ and marital status $(p=0.012)$; between central obesity and age $(p=0.018)$ and marital status $(p=0.007)$; between high fasting plasma glucose and sex $(p=0.033)$.

Although the sample was representative from a statistical viewpoint, the investigation did not consider students from all courses, nor eating habits and family antecedents. The participants' voices were not heard either, so as to understand their modus vivendi, which includes the motives that make them adopt inappropriate health behaviors. This important aspect would complement the data needed to elaborate public policies for the students at the investigated institution. Therefore, other qualitative or intervention studies are suggested focused on college students, so as to clarify important issues for the strengthening of regular physical exercise, a healthy diet and, consequently, the prevent of type 2 diabetes.

\section{References}

1. Ministério da Saúde (BR). Secretaria de Atenção à Saúde. Estratégias para o cuidado da pessoa com doença crônica: diabetes mellitus. Brasília (DF): Departamento de Atenção Básica; 2013.

2. Sociedade Brasileira de Diabetes. Cuidados de Enfermagem em Diabetes Mellitus. Manual de Enfermagem. São Paulo: Departamento de Enfermagem da Sociedade Brasileira de Diabetes; 2009. 171 p.

3. American Diabetes Association. Standards of Medical Care in Diabetes - 2011. Diabetes Care 2011;34(Suppl):11-61.

4. Marinho NBP, Vasconcelos HCA, Alencar AMPG, Almeida PC, Damasceno MMC. Diabetes mellitus: fatores associados entre usuários da estratégia saúde da família. Acta Paul Enferm. 2012;25(4):595-600.

5. Xu H, Song Y, You NC, Zhang ZF, Greenland S, Ford ES, et al. Prevalence and clustering of metabolic risk factors for type 2 diabetes among Chinese adults in Shanghai, china. BMC Public Health. 2010;10:683-90.

6. Lipman TH, Schucker MM, Ratcliffe SJ, Holmberg TBA, Baier SBA, Deatrick JA. Diabetes risk factors in Children: a partnership between nursig practioner and high school students. MCN Am J Matern Child Nurs. 2011; 36(1):56-62.

7. Barrett SC, Huffman FG, Johnson P, Campa A, Magnus M, Ragoobirsingh D. A cross-sectional study of Jamaican adolescents' risk for type 2 diabetes and cardiovascular diseases. BMJ Open. 2013;3(7):1-9.

8. Almeida VCF, Zanetti ML, Almeida PC, Damasceno MMC. Occupation and risk factors for type 2 diabetes: a study with health workers. Rev. Latino-Am. Enfermagem. 2011;19(3):476-84.

9. Macedo SF, Araujo MFM, Marinho NBP, Lima ACS, Freitas RWJF, Damasceno MMC. Risk factors for 
type 2 diabetes mellitus in children. Rev. Latino-Am. Enfermagem. 2010;18(5):936-42.

10. Vasconcelos HCA, Araújo MFM, Damasceno MMC, Almeida PC, Freitas RWJF. Risk factors for type 2 diabetes mellitus among adolescentes. Rev Esc Enferm USP. 2010;44(4):881-7.

11. Ashok P, Kharche JS, Joshi AR. Evaluation of risk for type 2 diabetes mellitus in medical students using Indian Diabetes Risk Score. Indian J Med Sci. 2011;65(1):1-6. 12. Vilarinho RMF, Lisboa MTL, Thiré PK, França PV. Prevalência de fatores de risco de natureza modificável para a ocorrência de Diabetes mellitus tipo 2. Esc Anna Nery. 2008;12(3):452-5.

13. Associação Brasileira de Empresas de Pesquisa (ABEP). Critério de Classificação Econômica Brasil. Dados com base no Levantamento Sócio Econômico - 2005 - IBOPE; 2008 [acesso 11 nov 2011]. Disponível em: http://www.abep.org/novo/FileGenerate.ashx?id=250 14. World Health Organization. Defining the problem of overweight and obesity. In: World Health Organization. Obesity: preventing and managing the global epidemic: report of a Who Consultation. Geneva; 2000. (WHO technical report series, 894).

15. Sociedade Brasileira de Cardiologia (SBC). VI Diretrizes Brasileiras de Hipertensão Arterial. Rev Bras Hipertens. 2010;17(1):57-60.

16. Madureira AS, Corseuil HX, Pelegrini A, Petroski EL. Associação entre estágios de mudança de comportamento relacionados à atividade física e estado nutricional em universitários. Cad Saúde Pública. 2009;25(10):2139-46. 17. Ministério da Saúde (BR). Secretaria de Vigilância em Saúde. Vigitel Brasil 2011. Vigilância de Fatores de Risco e Proteção para Doenças Crônicas por Inquérito Telefônico. Brasília: Ministério da Saúde; 2012.

18. Sira N, Pawlak R. Prevalence of overweight and obesity, and dieting attitudes among Caucasian and African American college students in Eastern North Carolina: A cross-sectional Survey. Nutr Res Pract. 2010;4(1):36-42.

19. Al Qauhiz NM. Obesity among saudi female university students: dietary habits and health behaviors. J Egypt Public Health Assoc. 2010;85(1):45-59.

20. Silva DAS, Quadros TMB, Gordia AP, Petroski EL. Associação do sobrepeso com variáveis sóciodemográficas e estilo de vida em universitários. Ciênc Saúde Coletiva. 2011;16(11):4473-9.

21. Lino MZR, Muniz PT, Siqueira KS. Prevalência e fatores associados ao excesso de peso em adultos: inquérito populacional em Rio Branco, Acre, Brasil, 2007-2008. Cad Saúde Pública. 2011;27(4):797-810.
22. Silva SRR, Arcuri EAM,Isabella APJ,Arcuri SM,Santos JLF .Adolescent hypertension identified with correct cuff and its cardiovascular and gestational problems after 29 years. Rev. Latino-Am. Enfermagem. 2014;22(1):3-10. 23. Barros ALBL, Vieira FS, Assis CC, Zeitoun SS. Alterações do nível pressórico e fatores de risco em graduandos de enfermagem. Acta Paul Enferm. 2009;22(6):773-8.

24. Martins MCC, Ricarte IF, Rocha CHL, Maia RB, Silva $V B$, Veras $A B$, et al. Pressão arterial, excesso de peso, e nível de atividade física em estudantes de universidade pública. Arq Bras Cardiol. 2010;95(2):192-9.

25. Uchiyama A, Shimizu T, Nakagawa T, Tanaka T. Association of hypertension with changes in the body mass index of university students. Environ Health Prev Med. 2008;13(5):271-80. 